\title{
Crowdfunding to Finance R\&D of Treatments for Neglected Tropical Diseases: Current Trends in and Future Potential
}

Safouane M. Benazzouz ${ }^{1,2,3}$, John Malkinson ${ }^{1}$ and Gergely Tóth ${ }^{1,4,5, *}$

${ }^{1}$ UCL School of Pharmacy. University College London. 29-39 Brunswick Square, Bloomsbury, London WC1N 1AX, United Kingdom

${ }^{2}$ University of Algiers 1. 2 Didouche Mourad Street, Algiers. 16000. Algeria

${ }^{3}$ Pasteur Institute of Algeria. Petit Staoueli Street. Dely Ibrahim, Algiers. 16320. Algeria

${ }^{4}$ Cantabio Pharmaceuticals, Palo Alto, California, USA

${ }^{5}$ TTK-NAP B - Drug Discovery Research Group - Neurodegenerative Diseases, Institute of Organic Chemistry, Research Center for Natural Sciences, Budapest, Hungary

* Corresponding author: email: toth.gergely@ ttk.hu, phone number: +36-1-382-6618 


\title{
Short summary statement
}

As crowdfunding to finance $R \& D$ for neglected tropical diseases has been underused, its promotion is necessary so that it can become a complementary financing source to conventional funding practices.

\begin{abstract}
A serious lack of funding exists for the research and development (R\&D) of therapeutics, diagnostics and preventive measures for neglected tropical diseases (NTDs). Crowdfunding to finance R\&D for NTDs has high promise as it is a new and alternate source of capital. This study aims to explore current trends of crowdfunding for R\&D for NTDs. Our study uncovers that while the number of crowdfunding campaigns for NTDs has been increasing since 2010, crowdfunding overall has not reached its full potential. Several factors contributing positively to the success of crowdfunding campaigns were identified, These and the promotion of the crowdfunding ecosystem could aid the unlocking of its potential as a complementary financing source to conventional funding practices of R\&D for NTDs.
\end{abstract}

Keywords: crowdfunding; alternative financing; neglected tropical diseases; research and development (R\&D). 


\section{Introduction}

Neglected tropical diseases (NTDs) such as dengue, leishmaniasis and trachoma affect around 1.6 billion people mainly in developing countries and have a high global health and economic disease burden (GDB). Nevertheless, only $0.18 \%$ of the global pharmaceutical R\&D expenditures were allocated to NTDs in 2018, which is strikingly low considering their GDB [1-3]. This stems from the low return on investment that the pharmaceutical industry can expect for financing the development of therapeutics for NTDs, largely because most of the patient populations for NTDs are located in developing countries where purchasing power for such drugs is limited [4]. For instance, trachoma, one of the leading causes of blindness globally, affects more than 95 million people mostly in developing countries, and has an estimated yearly economic burden between US\$2.9 and US\$5.3 billion [5]. Paradoxically, only US\$2.09 million was spent worldwide on R\&D for this disease in 2019 [2]. Besides its scarcity, the available funding for R\&D on NTDs is highly focused on some diseases that reflect the interests of their funders who are mainly the public sector, the philanthropic sector and the pharmaceutical industry. This hinders research on a large number of these diseases as a result of the lack of financing resources $[6,7]$.

Crowdfunding is the process of funding a project by raising small money contributions from large numbers of individuals. It is an alternative and new source of capital that may ultimately massively benefit biomedical research by increasing financing resources via facilitating the direct access of $R \& D$ projects to backers and their capital. Early-stage research, proof-of-concept studies and even clinical trials could particularly benefit from this alternative capital source for R\&D of therapeutics for NTDs [8,9].

While crowdfunding has been highlighted for its potential in financing $R \& D$ of therapeutics for NTDs, only five noteworthy campaigns were reported in the literature [8-13], consequently no thorough analysis of the crowdfunding campaigns for funding $R \& D$ of therapeutics for NTDs has been performed. Therefore, this study aims to present a detailed analysis of such past crowdfunding campaigns to report on the factors that determine the success of these campaigns. With this, our goal is to provide a framework by which successful crowdfunding campaigns can be performed to mitigate the scarce availability of funding in general. 


\section{Identification and analyses of crowdfunding campaigns}

Crowdfunding campaigns related to funding R\&D of therapeutics, diagnostics and preventive measures for NTDs were identified and analysed. The crowdfunding campaigns associated with NTDs were identified using the research engine Google and the search function of 19 crowdfunding platforms (CFPs). Due to the lack of consensus regarding the list of neglected diseases $[6,12,14,15]$, the 24 NTDs defined by the World Health Organization (WHO), as of 2018, were considered in this study [16]. Campaigns related to NTDs were sought using the "NTD designation(s)" on each CFP; this designation was associated to the keyword "crowdfunding" while searching on Google. In order to only consider the campaigns related to R\&D activities, inclusion and exclusion criteria were then applied (Table 1). Thirty-four campaigns (listed in Table S1) were selected and scrutinized for a data collection. The information collected was classified into "primary data" corresponding to 16 campaign features considered to be relevant for further analysis, and "secondary data" which are 7 features used for documenting purposes or not readily available (Table 1). The number of times the campaign was shared online, which reflects its visibility, would have been very informative, but this information was available only on a few platforms. In addition, the outcome of each campaign was determined as successful, moderately successful or unsuccessful when $>80 \%, 40-80 \%$ or $<40 \%$ of the funding target was pledged by the crowd, respectively. Lastly, the primary features of the campaigns were analysed using descriptive statistics. The features contributing to campaign success were determined by conducting statistical analyses using the $95 \% \mathrm{CI}$ of the Odds Ratio (OR). A Haldane-Anscombe correction was applied where zero values were observed in these analyses $[17,18]$.

\section{Analyses of identified crowdfunding campaigns}

Thirty-four crowdfunding campaigns were found to have sought funding for $R \& D$ activities related to therapeutics, diagnostics and prophylactic methods for NTDs until July 2018 , raising $\$ 386,225$ in contribution. The number of campaigns retrieved was considerably higher than those previously reported in the literature $[9,10,12]$. Nevertheless, crowdfunding had been an underexploited funding mechanism to fund innovation on NTDs when compared to the 250,000 medical campaigns launched each year on the CFP GoFundMe; these campaigns raise more than $\$ 650$ million annually $[19,20]$. The first campaign identified was launched only in 2010, and a substantial increase of the number of campaigns has been observed since then 
(Fig. 1a). Around half of the campaigns (16 out of 34) were relevant to multiple diseases, which was mainly due to the campaigns (10) funding R\&D on devices used to control disease vectors. On the other hand, 15 out of the WHO's 24 NTDs were never the subject of any crowdfunding campaigns. Eight campaigns were associated with diseases among the top five of the mostfunded NTDs in 2016, which suggests that despite the conventional funding available, researchers were still looking for additional funds [6]. While NTDs affect developing countries almost exclusively, 91\% of the campaigns (31 campaigns) were instigated from developed countries with about two-thirds (21 campaigns) originating from the USA alone.

The funds sought by the campaigns were relatively small. The average amount of funding raised by the campaigns was US\$11,359 per campaign, while 59\% of the campaigns raised less than US\$5,000. 53\% of the campaigns managed to reach their funding target, while $35 \%$ of the campaigns could not reach $40 \%$ of their targeted amount (Fig. 1e). Campaigns that could not reach their funding target were still able to collect the pledged funds. Interestingly, the average amount raised and the proportion of successful campaigns were comparable to the average amount pledged per campaign (US\$9,239) [21] and success rate $(36.0 \%)$ observed on Kickstarter [22]. Overall, the average amount of funds raised by the campaigns is considerably lower compared to typical research grants funded in developed countries.

Various R\&D activities were funded through the campaigns (Fig. 1d) but research of new devices to control disease vectors was most frequently considered for crowdfunding (10 campaigns; 29\%). Interestingly, basic and translational research were funded in more campaigns compared to clinical development, $24 \%$ versus $2 \%$ of all campaigns, respectively (Fig. 1d). Crowdfunding was also used to support observational studies and to develop innovative diagnostics in $15 \%$ and $12 \%$ of all campaigns, respectively. Crowdfunding for clinical research was shown to achieve its funding target in most campaigns, yet it was only considered as a complementary funding source [23].

\section{Factors contributing to the success of campaigns}

The analysis of the factors contributing to campaign success, summarized in Table 2, suggest that some basic features of the campaigns had the ability to impact positively the chances of their success. These features are the following: the identity of the seeker of the 
funds, the platform used, the crowdfunding model, scientific peer review of the campaign, the use of video to introduce the fund-seeking team and project, the funding target flexibility and the campaign duration. These features are discussed in more detail below.

Researchers affiliated to universities were associated with high odds of achieving their funding targets (95\% CI: 2.0-173.9) and a remarkably high success rate (83\%). The success of academic researchers in these fundraising campaigns is likely due to the general trust of the crowd in scientists working in non-profit research institutions. Conversely, the identity of fund seekers such as students, researchers affiliated with charitable organizations, for-profit organizations or research institutes, or non-affiliated researchers had no measurable impact on the success rate of the campaigns. Campaigns that were subjected to some sort of scientific review had higher odds of success (95\% CI: 9.7-4893.8) compared to unreviewed campaign. Clearly, scientific peer review increased the confidence of potential supporters of the campaigns. University CFPs had a high success rate when all of the targeted funds of the campaigns were raised, but this was not statistically significant (0.7-265.5) due to the low number (5) of such campaigns identified.

Two distinct crowdfunding models were applied by the examined campaigns, the donation- and the reward-based models. Crowd-investing models were not used probably due to the lack of companies focused on NTD therapeutic research. Moreover, we observed that offering a non-financial return was associated with high success odds (5.1-2082.2). The rewards offered were either free access to study results or symbolic perks such as acknowledgments to contributors, photo albums, video diaries, magazines, 3D-printed items and in one case a prototype of the device in development. On the contrary, all campaigns not offering rewards failed to reach their targets and had low chances of success $(0.0-0.2)$.

The so-called "all-or-nothing campaigns", which do not allow the fund seekers to keep the pledged funds in the case that the funding target is not reached, had high success odds (7.03,065.1), while the "keep-it-all campaigns" were associated with low chances of success $(0.0$ 0.1 ). However, most of the all-or-nothing campaigns (11 out of 15) were scientifically reviewed, which might have contributed to their successful outcomes.

Moreover, the use of a video in the campaigns had a positive effect on their odds of success (1.3-25.1) compared to those not featuring videos $(0.0-0.8)$. In fact, it is likely that potential campaign supporters could have obtained a better understanding of projects and 
developed more trust toward the campaign and its seekers through the use of videos. Lastly, it is noteworthy that successful campaigns did not last more than 3 months, which should be taken into consideration in campaign planning.

Although several properties did not have a statistically significant impact on success odds, some features such as the use of a pitch word count ranging between 500 and 1,000 words and some $R \& D$ activities (drug discovery, $R \& D$ on vector control devices and observational research) had remarkably high success rates. Therefore, having all the discussed features appropriately considered and built-in the in a campaign should increase the probability of success of the campaigns.

\section{Promotion of crowdfunding for NTDs}

In order to increase the number of crowdfunding campaigns to fund R\&D for NTDs, global educational campaigns should be developed to synergistically raise awareness of NTDs and to familiarize people with crowdfunding. Moreover, an efficient way to unlock the potential of crowdfunding for NTDs would be through the creation of a global and trusted CFP dedicated to fund R\&D on NTDs. Such a CFP should allow multi-lingual pitches for enhanced global reach. Ideally, a renowned non-profit organization in this field would launch or endorse the platform, which would build the public's trust in it. This CFP could also facilitate the management of worldwide educational campaigns.

People in developed countries often have higher financial resources but are not affected by NTDs, while people in developing countries are more affected by these diseases but have more limited financial resources and less access to online payment methods. Therefore, people in developing countries are likely to have a lower impact on crowdfunding for NTDs. Thus, the most practical approach could be for fund seekers to raise financing at a global level through English-written crowdfunding campaigns. With this said, a dual approach at a global (in English) and local (in a developing country) levels may prove to be the most effective. In a perspective by Özdemir, an example is outlined in which it is suggested that if 400 million people, who are at risk of being affected by NTDs in the Middle East and North Africa region, could contribute only one cent to crowdfunding campaigns for NTDs, \$4 million could be raised [11]. 


\section{Limitations of the study}

It is important to note that the search for crowdfunding campaigns in this study was conducted in English and that campaigns promoted in other languages were not included. The number of these campaigns is, however, presumed to be significantly lower than the campaigns promoted in English as the latter have a global reach and are more likely to be supported. Indeed, the web content is dominated by English, and English-speaking individuals were found to access the Internet up to four times more often compared to non-English speakers [27-29].

Despite the fact that NTDs affect mostly developing countries, crowdfunding was considered as a source of capital for R\&D of NTDs in these countries in only three campaigns according to our study. This could be explained by the fact that crowdfunding is not welldeveloped in the affected countries. Indeed, the share of the southern hemisphere - which is the most affected by NTDs - of the global crowdfunding market is less than $1 \%$ [24]. Nonetheless, China, which is located in the northern hemisphere, has the biggest crowdfunding market volume globally and is moderately affected by these diseases $[25,26]$. This points the fact that some local campaigns launched in Chinese might not have been retrieved in this research.

Another limitation of this study was that its scope was restricted to the WHO's list of 24 NTDs, leading to identification of only 34 crowdfunding campaigns and potentially a reduced number of success factors.

\section{Future directions in research on crowdfunding for NTDs}

An interesting additional research prospect could be to carry out a more comprehensive analysis by considering all 42 diseases qualified in the literature as neglected, which would generate more data and consequently increase the sensitivity of the analysis of success factors. Carrying out similar studies in other languages, especially in Chinese, would help map out campaigns with a local reach. Another prospect could be to conduct a global survey to estimate the number of potential contributors to crowdfunding campaigns to finance R\&D on NTDs, and to understand their motivations in doing so. The geographic coverage of such survey should be designed in a way that it identifies the crowdfunding marketplaces that would support these campaigns. 


\section{Concluding remarks}

A critical lack of funding exists for the R\&D of therapeutics and diagnostics for NTDs. Crowdfunding to raise capital for financing these $R \& D$ projects has high potential to provide much-needed funds to researchers. This study finds that while crowdfunding of R\&D projects for NTDs has been increasing since 2010, it is still underused and has not been applied to its full potential. Moreover, key crowdfunding campaign features, such as scientific peer review of the campaign, use of video, university affiliation of fund-seeker and use of reward-based crowdfunding model, were found to be correlated with increasing the chances of success of a campaign. These may be implemented by researchers executing crowdfunding to finance $R \& D$ for NTDs to increase the likelihood of their success.

Given that limited investment in R\&D is being made by leading pharmaceutical companies in developing diagnostics and therapeutics for NTDs, crowdfunding can play an important role in providing a new source of capital for such projects. To achieve this, the concept of crowdfunding and its execution should be promoted to researchers working on these diseases, particularly in developing countries. The foreseen growth of crowdfunding in general, and its rapidly evolving global regulatory environment, should also amplify its potential.

\section{Acknowledgements}

S.M.B. was supported by the Chevening Scholarships, the UK government's global scholarship programme, funded by the Foreign and Commonwealth Office (FCO) and partner organisations, and the University College London. G.T. thanks the Hungarian Brain Research Program (2017-1.2.1-NKP-2017-00002) for support.

\section{Conflict of interest}

G.T. is an employee and shareholder of Cantabio Pharmaceuticals. 


\section{References}

[1] Torreele, E., Usdin, M., \& Chirac, P. (2004). A needs-based pharmaceutical R\&D agenda for neglected diseases. Paper prepared for the WHO Commission on Intellectual Property Rights, Innovation and Public Health. Retrieved from https://www.who.int/intellectualproperty/topics/research/Needs\%20based\%20R\&D\%20for\% 20neglected\%20diseases\%20Els\%20Pierre\%20Martine.pdf [Accessed June 24, 2018].

[2] Policy Cures Research (2020). Neglected Disease Research and Development: Uneven Progress. Retrieved from https://s3-ap-southeast-2.amazonaws.com/policy-cures-websiteassets/app/uploads/2020/02/11150341/G-Finder2019.pdf [Accessed September 25, 2020].

[3] Mikulic, M. (2020). Total global spending on pharmaceutical research and development from 2012 to 2026. Retrieved from https://statista.com/statistics/309466/global-r-and-dexpenditure-for-pharmaceuticals/ [Accessed September 25, 2020].

[4] Mestre-Ferrandiz, J., Sussex, J., \& Towse, A. (2012). The R\&D cost of a new medicine. Office of Health Economics. Retrieved from https://www.ohe.org/system/files/private/publications/380\%20\%20R\%26D\%20Cost\%20NME\%20Mestre-Ferrandiz\%202012.pdf [Accessed June 23, 2018].

[5] WHO (2020). Trachoma: Key facts. Retrieved from https://who.int/news-room/factsheets/detail/trachoma [Accessed September 25, 2020].

[6] Chapman, N. et al. (2017). Neglected disease research and development: Reflecting on a decade of global investment. Retrieved from http://policycuresresearch.org/downloads/Y10 G-FINDER full report.pdf [Accessed June 29, 2018].

[7] EvaluatePharma (2016). World preview 2016, Outlook to 2022. Retrieved from http://info.evaluategroup.com/rs/607-YGS-364/images/wp16.pdf [Accessed June 28, 2018].

[8] Renwick, M. J., \& Mossialos, E. (2017). Crowdfunding our health: Economic risks and benefits. Social Science \& Medicine, 191, 48-56.

https://doi.org/10.1016/j.socscimed.2017.08.035

[9] Del Savio, L. (2017). The Place of Crowdfunding in the Discovery of Scientific and Social Value of Medical Research. Bioethics, 31(5), 384-392. https://doi.org/10.1111/bioe.12339

[10] Riccardi, G., Old, I. G., \& Ekins, S. (2017). Raising awareness of the importance of funding for tuberculosis small-molecule research. Drug Discovery Today, 22(3), 487-491. https://doi.org/10.1016/j.drudis.2016.09.012

[11] Özdemir, V. et al. (2013). Crowd-funded micro-grants for genomics and "big data": An actionable idea connecting small (Artisan) science, infrastructure science, and citizen philanthropy. OMICS A Journal of Integrative Biology, 17(4), 161-172.

https://doi.org/10.1089/omi.2013.0034

[12] Pollastri, M. (2015). Data sharing for neglected tropical disease drug discovery: Creating a framework for reducing redundancy and improving global collaboration. Annals of Global Health, 81(1), 196. https://doi.org/10.1016/j.aogh.2015.02.951 
[13] InfoDev/The World Bank (2013). Crowdfunding's Potential for the Developing World. Finance and Private Sector Development Department. Washington, DC. Retrieved from http://www.infodev.org/infodev-files/wb_crowdfundingreport-v12.pdf [Accessed June 30, 2018].

[14] Ivinson, A. J. (2002). Macroeconomics and Health: Investing in Health for Economic Development. Nature Medicine, 8(6), 551-552. https://doi.org/10.1038/nm0602-551b

[15] PLoS Medicine Editors (2005). A New Era of Hope for the World's Most Neglected Diseases. PLoS Medicine, 2(9), e323. https://doi.org/10.1371/journal.pmed.0020323

[16] WHO (2018). Neglected tropical diseases. Retrieved from http://who.int/neglected_diseases/diseases/en/ [Accessed June 28, 2018].

[17] Deeks, J. J., \& Higgins, J. P. T. (2010). Statistical algorithms in Review Manager 5, 111. Retrieved from https://training.cochrane.org/handbook/statistical-methods-revman5 [Accessed July 3, 2018].

[18] Szumilas, M. (2010). Explaining odds ratios. Journal of the Canadian Academy of Child and Adolescent Psychiatry, 19(3), 227-229.

[19] GoFundMe. (n.d.). Get help with medical fundraising. Retrieved from https://gofundme.com/start/medical-fundraising [Accessed January 29, 2021].

[20] McClanahan, C. (2018). People are raising \$650 million on GoFundMe each year to attack rising healthcare costs. Retrieved from

https://www.forbes.com/sites/carolynmcclanahan/2018/08/13/using-gofundme-to-attackhealth-care-costs $/ ? \mathrm{sh}=62 \mathrm{a} 5 \mathrm{bd} 8 \mathrm{~b} 2859$ [Accessed January 29, 2021].

[21] Kickstarter Stats (2018). Retrieved from https://kickstarter.com/help/stats [Accessed July $11,2018]$.

[22] Statista Research Department (2018a). Percentage of successfully funded Kickstarter projects as of April 2018. Retrieved from https://statista.com/statistics/235405/kickstarterproject-funding-success-rate/ [Accessed September 26, 2020].

[23] Sharma, A., Khan, J., \& Devereaux, P. J. (2015). Is crowdfunding a viable source of clinical trial research funding? The Lancet, 386(9991), 338. https://doi.org/10.1016/S0140$\underline{6736(15) 61407-6}$

[24] Crowdfunding Statistics (2020). Retrieved from https://blog.fundly.com/crowdfundingstatistics/ [Accessed January 29, 2021].

[25] Qian, M.-B. et al. (2019). Neglected tropical diseases in the People's Republic of China: progress towards elimination. Infectious Diseases of Poverty, 8(1), 86.

https://doi.org/10.1186/s40249-019-0599-4

[26] Statista Research Department (2018b). Volume of funds raised through crowdfunding in selected countries worldwide in 2018. Retrieved from

https://statista.com/statistics/1078229/global-crowdfunding-volume-worldwide-by-country/ [Accessed January 29, 2021]. 
[27] Nunberg, G. (2001). Will the internet always speak English? Retrieved from https://prospect.org/features/will-internet-always-speak-english/ [Accessed January 29, 2021].

[28] Kenny, C. (2002). Information and Communication Technologies for Direct Poverty Alleviation: Costs and Benefits. Development Policy Review, 20(2), 141-157.

https://doi.org/10.1111/1467-7679.00162

[29] Usage statistics of content languages for websites (2021). Retrieved from https://w3techs.com/technologies/overview/content_language [Accessed January 29, 2021]. 